\title{
NEW RECORD OF ABBREVIATA LEPTOSOMA GERVAIS, 1848 (SPIRURIDA: PHYSALOPTERIDAE) INFECTION IN TWO SPECIES OF LIZARDS IN NORTH AND SOUTH SINAI, EGYPT
}

\author{
Samar F. Harras*; Rasha A. Elmahy \\ Zoology Department, Faculty of Science, Tanta University, Gharbia, Egypt
}

\author{
Article History: \\ Received: 23 June 2019 \\ Revised: 17 July 2019 \\ Accepted: 23 July 2019 \\ Published Online: \\ 2 August 2019 \\ Keywords: \\ Abbreviata leptosoma \\ Egyptian lizards \\ Electron microscope \\ Light microscope \\ Morphological description \\ *Correspondence: \\ Samar Harras \\ Zoology Department, Faculty \\ of Science, Tanat University \\ Gharbia, Egypt \\ E-mail: \\ samar.harras@science.tanta. \\ edu.eg
}

\begin{abstract}
Studies on parasitic nematode infection in lizards are rare, and the available literature on their accurate morphological description especially by scanning electron microscopy (SEM) is lacking. Therefore, the aim of the present work is to identify new records of nematode parasites infecting Agamidae lizards, which are widely distributed in North and South Sinai; this entails giving a full morphological picture using light microscopy and SEM. Seventeen samples of Trapelus mutabilis and ten samples of Pseudotrapelus sinaitus (collected from North and South Sinai) were dissected and examined for their nematode parasitic infection. Adult nematodes were collected from the stomach and the upper part of the small intestine, identified, and fully described using light microscopy and SEM. Abbreviata leptosoma was collected for the first time from Egyptian T. mutabilis and P. sinaitus in a prevalence of $11.8 \%$ and $30.0 \%$ with mean intensity \pm standard deviation equals $8.5 \pm 7.8$ and $4.3 \pm 3.2$, respectively. A. leptosoma was identified based on the morphological characteristics of both male and female including the cephalic denticulation with 5-8 elements between submedian teeth and lateral tooth, absence of denticulate crest at the dorsal and ventral angles of the mouth, presences of two branched uteri and very unequal dissimilar spicules. The study gives a full SEM description of A. leptosoma. Thus, North and South Sinai are considered as new geographical localities for A. leptosoma infecting Agamidae lizards.
\end{abstract}

\section{INTRODUCTION}

Relatively little information is available worldwide on the parasitic fauna of reptiles compared to other vertebrates ${ }^{[1,2]}$, and rarely explored in lizards in respect of its taxonomic aspects ${ }^{[3]}$. One of the most abundant and widespread reptile species in Africa belongs to family Agamidae, which represented by five genera. The genus
Trapelus has a broad distribution across North Africa into the Middle East to Asia. Trapelus genus is characterized by short, thick heads deeply sunken tympana and few spiny scales above their ear opening ${ }^{[4]}$. Five species occur in northern Africa: T. mutabilis, T. pallidus in Egypt, T. schmitzi in Algeria and Niger, T. tournevillei in Algeria and Tunisia, and T. savignii at the 
east of the Nile River ${ }^{[4,5]}$. T. pallidus was considered a junior synonym of T. mutabilis, but regarded again as a valid species by other scientists ${ }^{[6,7]}$ who pointed out the differences in morphology, coloration, behaviour, and habitat of these species, and mentioned that $T$. pallidus occurs entirely in east of the Nile, whereas T. mutabilis occurs in west of the Nile. T. pallidus differs from T. mutabilis in having a matrix of comparatively uniform smooth dorsal scales with some scattered longer ridged scales ${ }^{[4]}$. In contrast, T. mutabilis has heterogamous dorsal scalation with scattered enlarged scales $^{[4]}$. Nowadays, the reptile database considered $T$. pallidus as a synonym to T. mutabilis $^{[8]}$. However, Pseudotrapelus sinaitus is a widely distributed Agamidae lizard in the Middle East including Egypt ${ }^{[6,9]}$. $P$. sinaitus was considered monotypic species; its adult male is characterized by depressed body, compressed tail base, and special coloration, as well as head dorsum and tail are bright blue, throat is blue, and the ventral side of the tail is white ${ }^{[10]}$.

Physalopteridae nematode family includes three subfamilies: Physalopterinae and Thubunaeinae infecting mainly reptile (absent in fish), while the third one is Proleptinae, is common in fish (absent in reptiles) ${ }^{[11]}$. The accurate identification of Physalopterinae species can only be made based on the characteristics possessed by both males and females in the following order of their importance: cephalic end, number of uteri, number and arrangement of male ventral papillae, shape and length of spicules, and position of vulva ${ }^{[12]}$. Physalopteric nematodes were divided into four genera: Physaloptera, Abbreviata, Skrjabinoptera, and Pseudophysaloptera. At the beginning of 21 century, Anderson ${ }^{[11]}$ added other three related genera: Pseudoabbreviata, Turgida, and Pentadentoptera. The genus Abbreviata was limited to Physalopteric nematodes with two uteri, four pairs of pedunculated papillae, and dissimilar spicules. The generic description was revised to include species that carry one externolateral tooth, one internolateral tooth, and two double submedian teeth on each pseudolabium $^{[13]}$. Usually the entire margin of pseudolabia is dentate. Morgan ${ }^{[13]}$ listed 27 species belonging to Abbreviata genus: seventeen are used reptiles as definitive hosts, nine are harboured by mammals, while the remaining one is found in various frogs and toads. Also, he provided a hostparasite list arranged by orders and families to facilitate a comprehensive view of hostparasite relationships. This list added an important taxonomic character based on the number and mode of origin of the uterine branches in the female worm, being 2-4 branches in reptilian host and 4 or more in mammalian hosts ${ }^{[13]}$.

Host-parasite relationship remains poorly described in lizard of Egypt in spite of the fact that full morphological studies of their helminthic parasites are very important to complete the gap of knowledge in taxonomy ${ }^{[14]}$. So, the aim of the present study was to identify and give detailed examination of new records of nematode species collected from both $T$. mutabilis and $P$. sinaitus lizards of North and South Sinai, Saint Catherine, Egyptian desert by both light microscope and scanning electron microscope (SEM).

\section{MATERIAL AND METHODS}

Twenty seven lizards (Reptilia: Agamidae) were examined for parasitic infection, seventeen from North Sinai $\left(30^{\circ} 366^{\prime} 51^{\prime \prime N}\right.$, $33^{\circ} 43^{\prime} 18^{\prime \prime E}$ ) and ten from South Sinai, Saint Catherine $\left(28^{\circ} 33^{\prime} 23^{\prime \prime} \mathrm{N}, 33^{\circ} 58^{\prime} 28^{\prime \prime} \mathrm{E}\right)$ areas. The collected hosts were anesthetized using chloroform. The gastrointestinal tracts were removed in $0.7 \%$ saline solution and each part was examined separately. Nematodes that found in the stomach and anterior part of small intestine were collected. Live specimens were washed in physiological saline and fixed (relaxed) in warm $70 \%$ ethanol with $10 \%$ glycerol. Specimens were cleared in lactophenol then mounted in glycerine jelly for light microscope examination and identification. Specimens were measured and examined using Olympus CX31 
microscope (Tokyo, Japan) and Zeiss Stemi 2000-C microscope (Oberkochen, Germany), and representative photomicrographs were taken with E-330DC $7.4 \mathrm{~V}$ digital camera. Drawings were made with the aid of camera Lucida.

For SEM, specimens were collected carefully and washed in isotonic saline solution, followed by phosphate-buffered saline, and fixed overnight in $3 \%$ glutaraldehyde in 0.1 mol phosphate buffer $(\mathrm{pH} 7.4)$ at $4^{\circ} \mathrm{C}$. Specimens were post fixed in $1 \%$ osmium tetraoxide then dehydrated through graded series of ethanol. Dehydration was performed in two changes of absolute ethanol and critical point dried. Specimens were mounted on stubs, coated with gold, and examined with a JEOL 5300-JSM SEM (Tokyo, Japan) at an accelerating voltage of $25 \mathrm{~K} . \mathrm{V}$. The identification follows Anderson et al. ${ }^{[15]}$ and Gibbons ${ }^{[16]}$ keys.

\section{RESULTS}

From three out of ten $P$. sinaitus and from two out of seventeen $T$. mutabilis examined for gastrointestinal parasitic infection, thirty samples of A. leptosoma belonging to family Physalopteridae were identified and morphologically described by light and SEM (Figures 1-3). The body of A. leptosoma is elongated (Figure 1a); the cuticle has fine transverse striations and dome-shaped head slightly set off from the rest of the body (Figure 3). Mouth is surrounded by two large pseudolabia; narrow laterally and elongated dorsoventrally almost to maximum width of worm, each bears one distinct apical wedge-shaped externolateral tooth. Near the base of each externolateral tooth, there is a smaller bifid internolateral tooth, conspicuous in dorsoventral view (Figures $2 b$ and 3a). On either side of the externolateral tooth, bifid submedian tooth is situated near the ventral and dorsal angles of each pseudolabium. A denticulate crest is present between the submedian teeth and the lateral tooth, while it is absent in the dorsal and ventral angles of the mouth. Along the inner surface of the lips, there are small delicate denticles (5-8 elements) between the submedian teeth and the lateral tooth. Two sessile cephalic papillae and one small amphid are also found on the external surface of each pseudolabium. The oesophagus is divided into a short muscular part, broad anteriorly and surrounded by a nerve ring, followed by a long glandular part (wider than muscular portion). Excretory pore is at a short distance posterior to origin of glandular oesophagus (Figures $2 \mathrm{a}$ and $3 \mathrm{~b}$ ).

The length of male A. leptosoma (five specimens) is $3.51-7.25 \mathrm{~mm}$; width at level of oesophago-intestinal junction is $0.27-0.4 \mathrm{~mm}$. Oesophagus is $1.42-1.65 \mathrm{~mm}$ in total length and $0.13-0.19 \mathrm{~mm}$ in width. Nerve ring is $0.12-0.18 \mathrm{~mm}$ from anterior extremity. Caudal alae are well developed and extend just beyond tip of the tail; they appear not to meet anteriorly. Alae are supported by four pairs of long, pedunculate, and precloacal papillae; of which the second pair is the longest. Another type of ventral cloacal papillae are sessile; two pairs are postcloacal (immediately posterior to cloaca) and three are precloacal (one pair is anterolateral and one median papilla, immediately situated anterior to cloaca). Three pairs of short pedunculate or sessile caudal papillae are found; of which central pair is closer to anterior pair. Ventral surface of tail and ventral median surface of alae are lined by tubercles that originate anterior to cloaca and run posteriorly in more or less longitudinal rows, converging on cloaca, and extending in parallel rows to level of posterior-most caudal papillae. There are two unequal and dissimilar spicules; the right one is $0.13-0.23 \mathrm{~mm}$ long, well sclerotised, stout, curved ventrally, and terminating in broadly alate tip. The left spicule is $1.5-1.85 \mathrm{~mm}$ long, weakly sclerotised, thin, longer than the right and terminating in fine tip (Figures $1 b, 2 c$ and $3 \mathrm{c})$. Within the collection of A. leptosoma specimens, two males were found with eggs closed to the retracted left spicule (Figures $1 \mathrm{c}$ and $2 \mathrm{~d}$ ). 


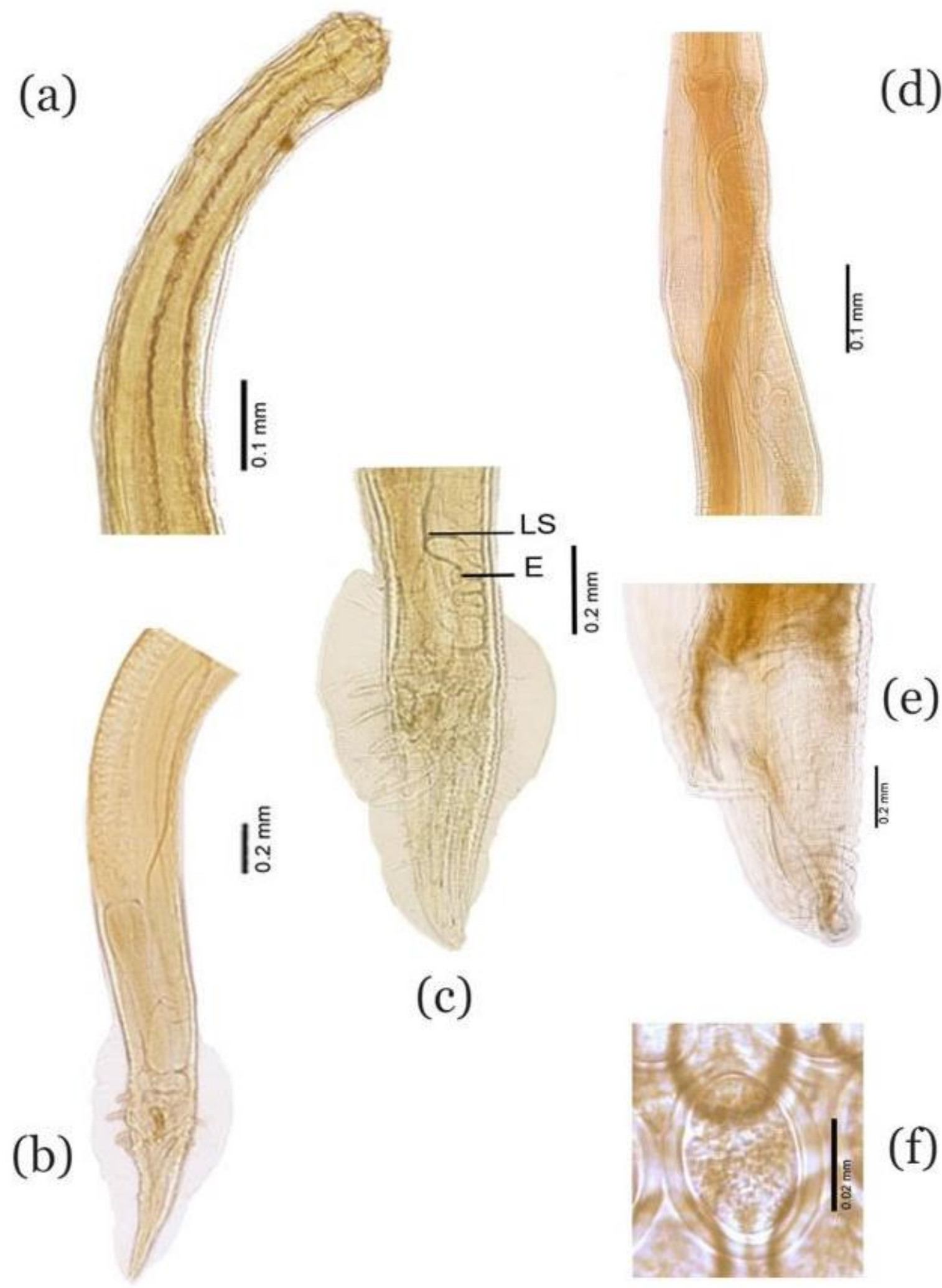

Figure 1: Photomicrographs of Abbreviata leptosoma: (a) anterior end of female, lateral view showing externolateral tooth, oesophagus, and nerve ring; (b) caudal end of male, subventral view showing papillae, right spicule, and left spicule; (c) high magnification of male specimen showing four pairs of pedunculated papillae, tubercles, and eggs (E) near the left spicule (LS); (d) female genitalia showing vaginal opening and two uterine branches; (e) posterior end of female showing the anal opening; (f) larvated egg, lateral view. 


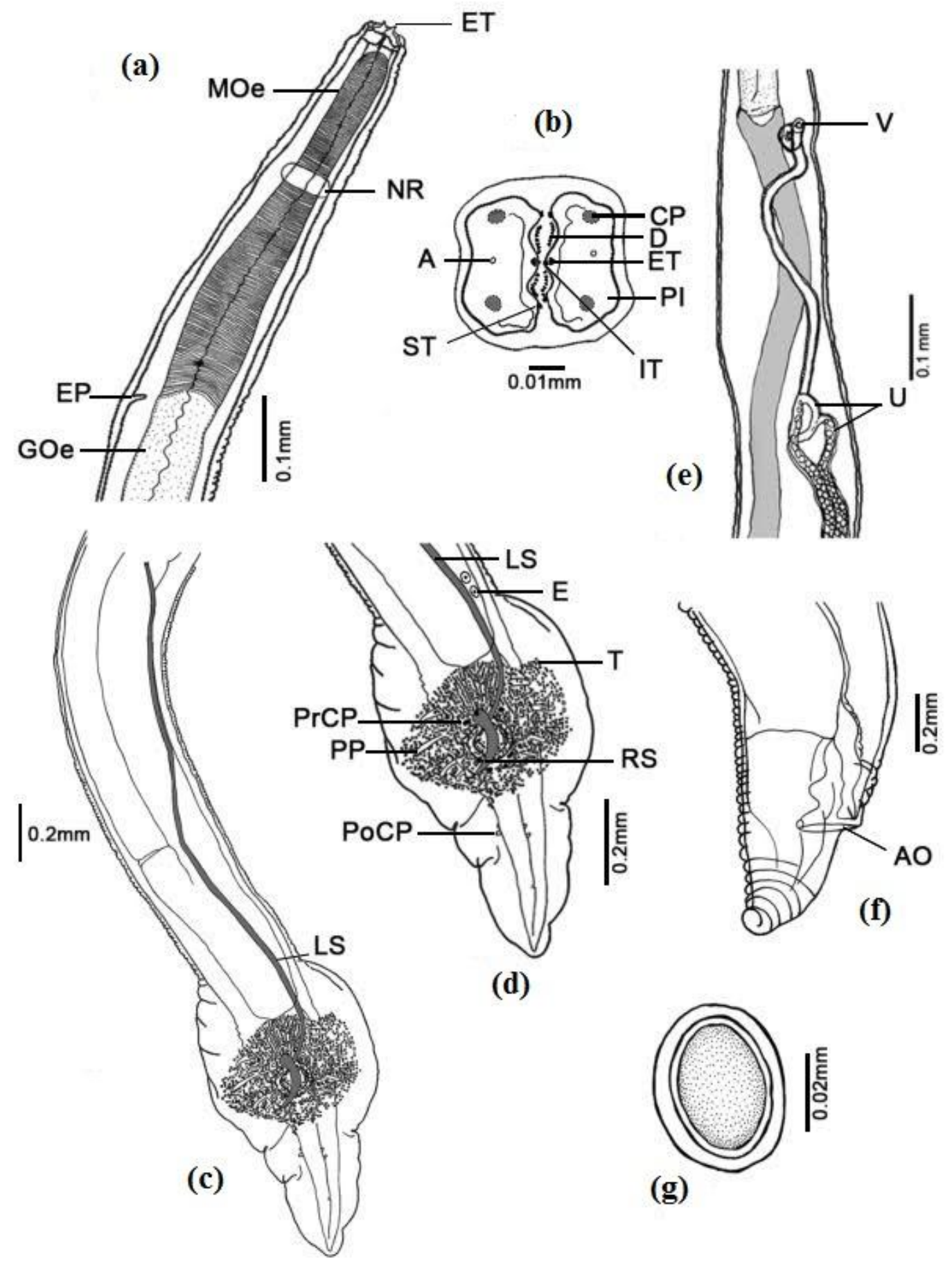

Figure 2: Diagrammatic representation of Abbreviata leptosoma: (a) anterior end of female, lateral view showing externolateral tooth (ET), muscular oesophagus (MOe), glandular oesophagus (GOe), nerve ring (NR), and excretory pore (EP); (b) enface view of cephalic region showing mouth, two large pseudolabia (Pl), externolateral tooth (ET), bifid internolateral tooth (IT), bifid submedian tooth (ST), small delicate denticles (D), two sessile cephalic papillae (CP), and one small amphid (A) on each pseudolabium; (c) caudal end of male, subventral view; (d) male specimen showing four pairs of pedunculated papillae (PP), postcloacal papillae (PoCP), precloacal papillae (PrCP), tubercles (T), right spicule (RS), left spicule (LS), and eggs (E) near the left one; (e) female genitalia showing vaginal opening (V) and two uterine branches (U); (f) posterior end of female showing the anal opening (AO); (g) larvated egg, lateral view. 

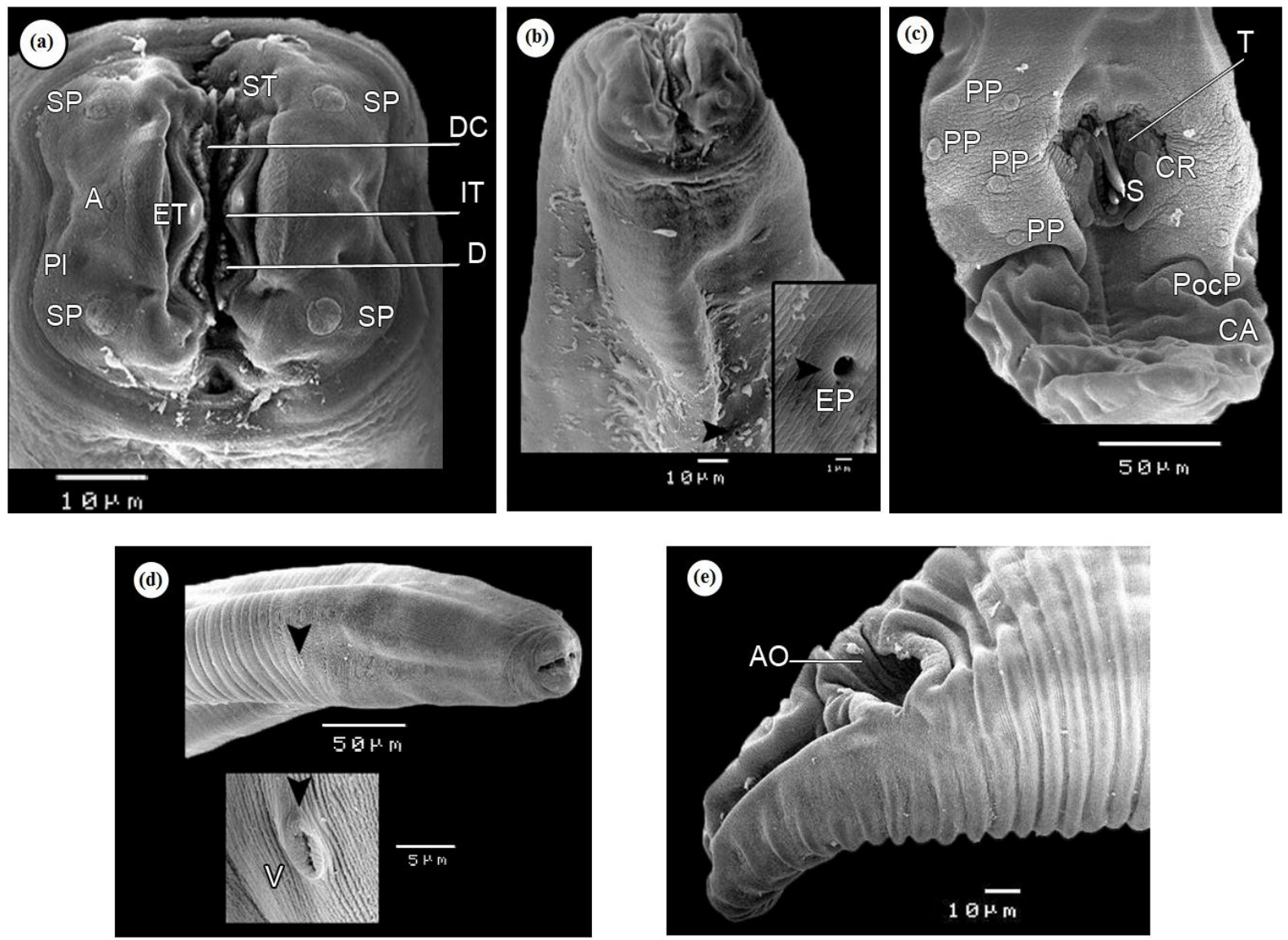

Figure 3: Abbreviata leptosoma SEM micrographs: (a) apical view, female, showing two pseudolabia (Pl), externolateral tooth (ET), internolateral tooth (IT), submedian tooth (ST), small delicate denticles (D), cephalic submedian papillae (SP), and two small amphids (A); (b) anterior end, female, lateral view showing excretory pore (EP); (c) caudal end of male, ventral view showing caudal alae (CA), cuticular ridges (CR), postcloacal papillae (PocP), pedunculated papillae (PP), tubercles (T), and spicules $(\mathrm{S})$; (d) anterior end of female, ventrolateral view showing vulva $(\mathrm{V})$; (e) posterior end of female, ventrolateral view showing the anal opening (AO).

The female A. leptosoma (five specimens) is $5.75-11.5 \mathrm{~mm}$ in length and $0.27-0.5 \mathrm{~mm}$ in maximum width. Oesophagus is 1.3 $1.75 \mathrm{~mm}$ in total length and $0.15-0.25 \mathrm{~mm}$ in width. The nerve ring is $0.18-0.32 \mathrm{~mm}$ from the anterior extremity (Figure 1a). The vulva is salient and situated 1.4-1.8 mm from the anterior extremity (Figure 3d). The uterus is bifurcated into 2 branches with common duct (Figures 1d and 2e). The anal opening situated just in front of the tip of the tail (Figures 1e and 2f). The eggs are oval, smooth, having thick shells, and measure $0.04 \times 0.03-0.05 \times 0.04 \mathrm{~mm}$ in diameter (Figures $1 \mathrm{f}$ and $2 \mathrm{~g}$ ). The tail is $0.2-0.4 \mathrm{~mm}$ long (Figures 1e, 2f and 3e).

\section{DISCUSSION}

In the current study, the described nematode specimens (collected from Agamidae lizards in Sinai) were assigned to the genus Abbreviata depending on their cephalic structure, where there is an externolateral tooth, an internolateral tooth, and two double pairs of submedian teeth on each lip, as well as the presence of two uterine branches. Nematodes in the genus Abbreviata are closely related to each other ${ }^{[15]}$. It has an extremely wide geographic range ${ }^{[17]}$, and low host specificity ${ }^{[18]}$. The detected nematode species in the present study was identified as A. leptosoma based on the cephalic denticulation, the number of 
elements between the submedian and lateral teeth, female with two uterine branches, as well as the very unequal spicules ${ }^{[15,16]}$. The literatures dealing with Abbreviata spp. are limited according to our knowledge. However, the present material corresponds perfectly to the description of A. leptosoma Gervais, 1848 collected from Varanus griseus and Uromastix acanthinurs in Algeria, but it is smaller in the total body length of both sexes (Table 1). The differences may be related to the smaller size of the present host T. mutabilis and $P$. sinaitus compared to large sized
Varanus griseus and Uromastix acanthinurus. A. leptosoma was mentioned in the list drawn by Morgan ${ }^{[13]}$ under two uteri group of Abbreviata. Nevertheless, A. graciles was also mentioned in the same group of two branched uteri Abbreviata that parasitizes Agamidae lizards of Uganda, but they have little unequal spicules compared to very unequal spicules in A. leptosoma detected in the present study ${ }^{[13]}$. Unfortunately, there is no available full SEM description for both A. leptosoma and A. graciles to compare between them.

Table 1: Comparison between Abbreviata leptosoma detected in both Egypt and Algeria lizards.

\begin{tabular}{|c|c|c|}
\hline & In Algeria ${ }^{[13]}$ & $\begin{array}{c}\text { In Egypt } \\
\text { (Current study) }\end{array}$ \\
\hline Host & $\begin{array}{l}\text { Uromastix acanthinurus } \\
\text { and Varanus griseus }\end{array}$ & $\begin{array}{l}\text { Trapelus mutabilis and } \\
\text { Pseudotrapelus sinaitus }\end{array}$ \\
\hline Site of infection & $\begin{array}{c}\text { stomach, oesophagus and } \\
\text { nasal cavity }\end{array}$ & $\begin{array}{l}\text { stomach lumen and anterior } \\
\text { part of small intestine }\end{array}$ \\
\hline Total male length $(\mathrm{mm})$ & $7.8-20.0$ & $3.51-7.25$ \\
\hline Total female length (mm) & $12.5-45.0$ & $5.75-11.5$ \\
\hline $\begin{array}{l}\text { Right spicule } \\
\quad(\mathrm{mm})\end{array}$ & $\begin{array}{l}\text { Short and thick } \\
\text { (0.15 long) }\end{array}$ & $\begin{array}{l}\text { Well sclerotised, stout, curved } \\
\text { ventrally, and terminating in } \\
\text { broadly alate tip (0.13-0.23 long) }\end{array}$ \\
\hline $\begin{array}{l}\text { Left spicule } \\
\quad(\mathrm{mm})\end{array}$ & $\begin{array}{l}\text { Thin } \\
1.92 \text { long }\end{array}$ & $\begin{array}{l}\text { Thin, weakly sclerotised } \\
(1.5-1.85 \text { long })\end{array}$ \\
\hline Egg size (mm) & $0.035 \times 0.052$ & $0.04 \times 0.03-0.05 \times 0.04$ \\
\hline
\end{tabular}

In Egypt, no one has reported before that A. leptosoma harbours Agama lizards as a definitive host. Two other species of Abbreviata namely A. sonsonoi (larval form) and A. aloisiisabaudiae were previously reported by Morgan ${ }^{[13]}$ from two Egyptian lizards Agama mutabilis and Agama alricollis respectively, however, they lacked a complete description and could not be classified. Interestingly, our observation of eggs that present in male specimens was previously observed in male physalopterids by Tromba el al. ${ }^{[19]}$; who stated that eggs in such cases must have been taken through large opening either the oral or anal one. It seems reasonable to accept his postulation that the eggs were not ingested but drawn or forced into the male during copulation.

In conclusion, the present study extended the host range of $A$. leptosoma to the Egyptian lizard, T. mutabilis and $P$. sinaitus and expanded its geographical locality, as a new record in North and South Sinai (Egypt) with fully descried details using both light microscope and SEM.

\section{Taxonomy summary}

Type hosts: T. mutabilis and $P$. sinaitus 
Collection site and time: North and South of Sinai (Egypt); September 2014 and August 2015

Site of infection: Stomach lumen and anterior part of small intestine

Prevalence: $11.8 \%$ (2 out of 17 hosts examined) with mean intensity $8.5 \pm 7.8$ (3-14 worm/host) in North Sinai; 30\% (3 out of 10 hosts examined) with mean intensity $4.33 \pm 3.21$ (2-8 worm/host) in South Sinai

\section{ACKNOWLEDGMENTS}

This research received no specific grant from any funding agency in the public, commercial or not-for-profit sectors. The author has no potential financial conflict of interest.

\section{AUTHORS' CONTRIBUTIONS}

SFH and RAE proposed the research idea, designed the experiments, performed the practical work, and identified the worm. SFH reviewed the literatures and data collection, as well as drafted the manuscript.

\section{REFERENCES}

[1] Sharpilo, V. P.; Biserkov, V. V.; Kostadinova, A. et al. (2001). Helminths of the sand lizard, Lacerta agilis (Reptilia, Lacertidae), in the Palaearctic: faunal diversity and spatial patterns of variation in the composition and structure of component communities. Parasitology, 123(Pt 4): 389-400.

[2] Martin, J. E. and Roca, V. (2004). Helminth infracommunities of Gallotia caesaris caesaris and Gallotia caesaris gomerae (Sauria: Lacertidae) from the Canary Islands (eastern Atlantic). J Parasitol, 90(2): 266-270.

[3] Dobson, A.; Lafferty, K. D.; Kuris, A. M. et al. (2008). Homage to Linnaeus: how many parasites? how many hosts? Proc Natl Acad Sci U S A, 105: 11482-11489.

[4] Wagner, P.; Melville, J.; Wilms, T. M. et al. (2011). Opening a box of cryptic taxa - the first review of the North African desert lizards in the Trapelus mutabilis Merrem, 1820 complex (Squamata: Agamidae) with descripttions of new taxa. Zoological Journal of the Linnaean Society, 163: 884-912.

[5] Wagner, P. and Böhme, W. (2007). A new species of the genus Trapelus Cuvier, 1816 (Squamata: Agamidae) from central Africa. Bonner Zoologische Beiträge, 55: 81-87.

[6] Disi, A. M.; Modrý, D.; Necas, P. et al. (2001). Amphibians and Reptiles of the Hasemite Kingdom of Jordan: an Atlas and field Guide. Chimari, Frankfurt am Main, Germany.

[7] Bahaa El Din, S. (2006). A Guide to the Reptiles and Amphibians of Egypt. American University in Cairo Press, Cairo, Egypt.

[8] Trapelus mutabilis (MERREM, 1820). The Reptile Database (http://reptiledatabase.reptarium.cz/species?genus= Trapelus\&species=mutabilis).

[9] Leviton, A. E.; Anderson, S. C.; Adler, K. et al. (1992). Handbook to Middle East Amphibians and Reptiles (Contributions to Herpetology). Ssar Pubns, Oxford, OH, USA.

[10] Moravec, J. (2002). A new subspecies of the Sinai agama Pseudotrapelus sinaitus from southern Syria and northern Jordan (Reptilia: Squamata: Sauria: Agamidae). Faun Abh Mus Tierkd Dresden, 23(7): 131-140.

[11] Anderson, R. C. (2000). Nematode Parasites of Vertebrates: their Development and Transmission. CABI Publishing, Wallingford, Oxon, UK.

[12] Morgan B. B. (1947). Host-parasite relationships and geographical distribution of the Physalopterinae (Nematoda). Transactions of the Wisconsin Academy of Sciences and Letters 38: 273-292.

[13] Morgan, B. B. (1945). The nematode genus Abbreviata (Travassos, 1920) Schulz, 1927. American Midland Naturalist 34(2): 485-490. 
[14] Pereira, F. B.; Luque, J. L. and Tavares, L. E. R. (2017). Redescription of the nematode parasites of lizards: Strongyluris oscari Travassos, 1923 (Heterakidae) from Brazil and Pharyngodon mamillatus (Linstow, 1897) (Pharyngodonidae) from Egypt. Acta Parasitologica 62(4): 805-814.

[15] Anderson, R. C.; Alian, G. and Willmott, S. (2009). Keys to the Nematode Parasites of Vertebrates. Archival Volume. CABI Publishing, Wallingford, Oxon, UK.

[16] Gibbons, L. M. (2010). Keys to the Nematode Parasites of Vertebrates. Supplementary Volume. CABI Publishing, Wallingford, Oxon, UK.

[17] Bain, O.; Mutafchiev, Y. and Junker,
K. (2014). Order Spirurida. In: Handbook of Zoology: Gastrotricha, Cycloneuralia and Gnathifera, Volume 2 Nematoda (Schmidt-Rhaesa, A., ed), pp. 661-732. De Gruyter, Berlin, Germany.

[18] Jablonski, D.; Vági, B. and Kardos, G. (2015). Abbreviata abbreviata (Rudolphi, 1819) as a new nematode parasite for Malpolon insignitus (Geoffroy Saint-Hilaire, 1827) recorded in Albania. Ecologica Montenegrina, 2(3): 194-196

[19] Tromba, F. G.; Chitwood, M. B. and Yunker Source, C. E. (1958). The occurrence of eggs in male Physalopterids and observations on the morphology of Abbreviata sonsinoi (V. Linstow, 1895) Shul'ts, 1927. J Parasitol, 44(2): 192-195.

\section{How to cite this article:}

Harras, S. F. and Elmahy, R. A. (2019). New Record of Abbreviata leptosoma Gervais, 1848 (Spirurida: Physalopteridae) infection in two species of lizards in North and South Sinai, Egypt. Egyptian Journal of Zoology, 72: 1-10 (DOI: 10.12816/ejz.2019.13977.1011). 


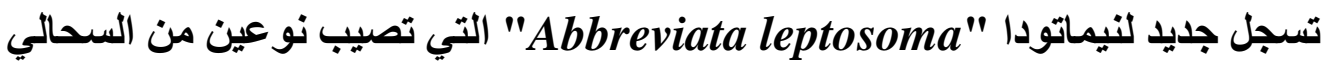 بشمال وجنوب سيناء فى مصر
}

\author{
سمر فؤاد هراس، رشا عادل الماحي \\ قسم علم الحيوان، كلية العلوم، جامعة طنطا، الغربية، جمهورية مصر العربية
}

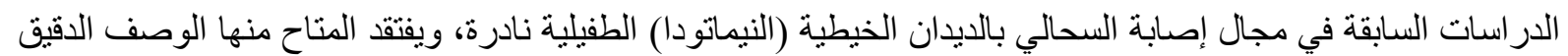

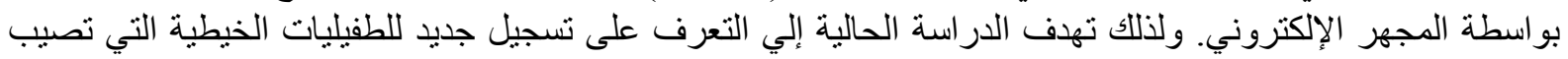

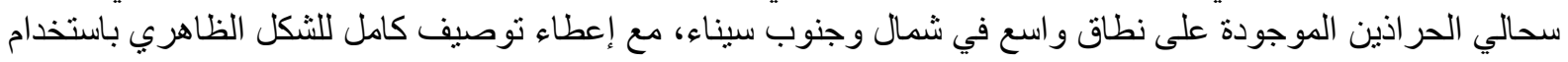

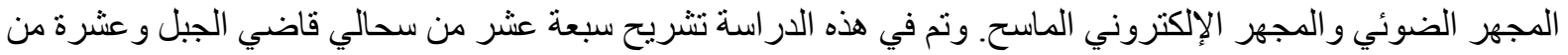

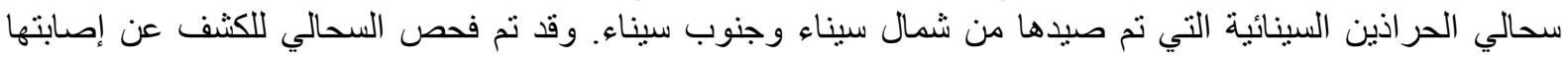

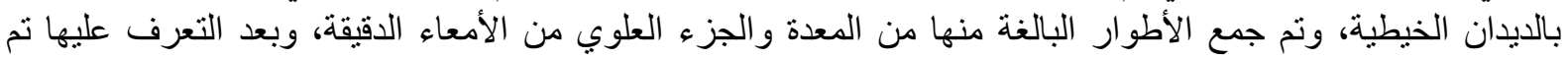

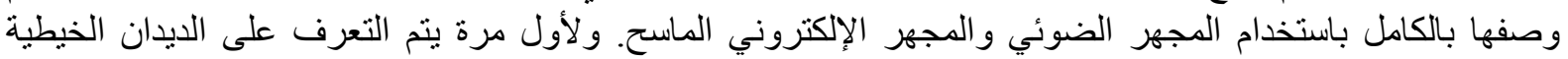

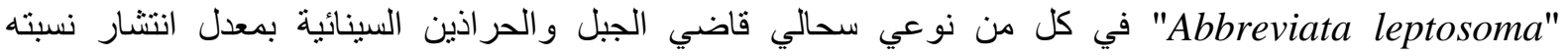
المئوية هي 11.8 و 30.0 مع منوسط شدة مقداره

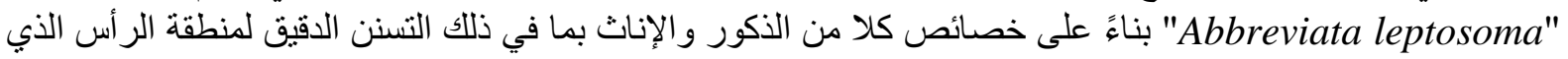

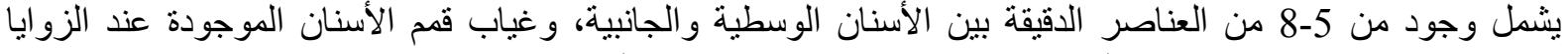

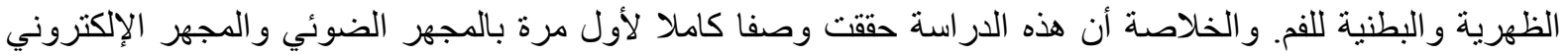

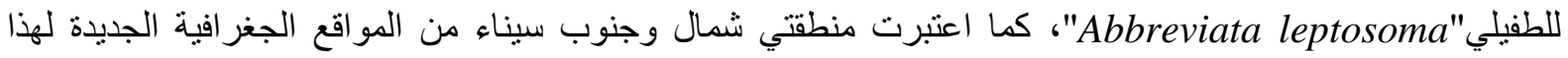
الطفيلي الذى يصيب سحالي قاضي الجبل و الحر اذين السينائية فى مصر . 